\title{
Guanidino compounds that are increased in hyperargininemia inhibit GABA and glycine responses on mouse neurons in cell culture
}

\author{
Peter P. De Deyn ${ }^{\mathrm{a}, \mathrm{c}}$, Bart Marescau ${ }^{\mathrm{c}, \mathrm{d}}$ and Robert L. Macdonald ${ }^{\mathrm{a}, \mathrm{b}}$ \\ Departments of ${ }^{a}$ Neurology and ${ }^{b}$ Physiology, University of Michigan, Ann Arbor, MI (U.S.A.), ${ }^{c}$ Laboratory of Neurochemistry and \\ ${ }^{d}$ Laboratory of Neuropharmacology, Born-Bunge Foundation, University of Antwerp, Antwerp (Belgium)
}

(Received 20 July 1990; revision received 20 November 1990; accepted 27 November 1990)

Key words: Guanidino compounds; Hyperargininemia; GABA responses; Glycine responses; Cultured neurons

\begin{abstract}
The effects of arginine, homoarginine, $\alpha$-keto- $\delta$-guanidinovaleric acid and argininic acid (guanidino compounds that were found to be increased in hyperargininemia) were evaluated on responses to $\gamma$-aminoburtyric acid (GABA) and glycine (Gly) on mouse neurons in primary dissociated cell culture. GABA and Gly were applied iontophoretically and intracellular microelectrode recording techniques were used.

The guanidino compounds rapidly and reversibly inhibited both GABA and Gly responses. The guanidino compounds inhibited GABA responses in a concentration-dependent manner and inhibited Gly responses at a concentration of $10 \mathrm{mM}$. Argininic acid was the most potent in reducing inhibitory amino acid responses, followed in decreasing potency by $\alpha$-keto- $\delta$-guanidinovaleric acid, homoarginine and arginine. The guanidino compounds were equally potent in decreasing Gly and GABA responses. Co-application of CGS 9896, a benzodiazepine receptor antagonist, did not antagonize the guanidino compound-induced inhibition of GABA responses. These findings suggest that the guanidino compounds inhibited responses to the inhibitory neurotransmitters GABA and Gly by blocking the chloride channel. This effect might underlie the in vivo epileptogenicity of some of the guanidino compounds and might contribute to the pathogenesis of seizures in hyperargininemia.
\end{abstract}

\section{INTRODUCTION}

Hyperargininemia is a rare inborn error of metabolism and is characterized by a deficiency of arginase, the last enzyme of the urea cycle, which converts arginine to urea and ornithine. The first

Correspondence to: Robert L. Macdonald, Dept. of Neurology, University of Michigan, Medical Center, Neuroscience Laboratory Building, 1103 East Huron Street, Ann Arbor, MI 48104, U.S.A. clinical and biochemical descriptions date from 1969 and $1970^{37-39}$. At present, hyperargininemia has been diagnosed in at least 32 children of 27 kindreds scattered all over the world ${ }^{1,3,4,9,12,13}$, $20,21,27,28,31,35,36,40,42$. The disease is autosomal recessive and a variety of neurological complications have been reported including mental deterioration, progressive spasticity and seizures which are not temporally related to hyperammonemia.

The hyperammonemia is not persistent and is less pronounced than in other urea cycle disorders 
and even absent in certain hyperargininemia patients. It has been suggested that ammonia is not the sole toxic agent in this disease, but that arginine and/or its metabolites, the guanidino compounds, might contribute to at least some of the neurological complications of this disease. Indeed, several guanidino compounds, some of which were previously shown to be experimental convulsants, were found to consistently accumulate in biological fluids of hyperargininemic patients ${ }^{17,18}$. As a consequence of the arginase deficiency, the serum and cerebrospinal fluid (CSF) arginine and homoarginine levels are increased in hyperargininemia. Analytical results indicate that the secondary catabolic pathway of arginine, which is most activated in this disease, involves transamination with the formation of $\alpha$-keto- $\delta$-guanidinovaleric acid. Moreover, the reduction of $\alpha$-keto- $\delta$-guanidinovalcric acid with the formation of argininic acid was also shown to be pronounced (see Fig. 1). Activation of this secondary pathway results in increased serum and CSF concentrations of $\alpha$-keto$\delta$-guanidinovaleric acid and argininic acid. Both $\alpha$ keto- $\delta$-guanidinovaleric acid and homoarginine were shown experimentally to be convulsant after topical application to the rabbit and rat sensorymotor cortex ${ }^{16,41}$. To our knowledge, the epileptogenicity of argininic acid has not been studied. Arginine did not alter the electroencephalogram after application to the sensory-motor cortex in rabbits at a concentration of $0.1 \mathrm{M}^{16}$.

A reduction in central nervous system GABAergic inhibition has been suggested to be a cause of epilepsy ${ }^{14,19,24,30}$. Several convulsants, including bicuculline, picrotoxin, penicillin, d-tubocurarine and pentylenetetrazol, have been shown to be GABA receptor antagonists, blocking the inhibitory action of GABA by interacting with either the
GABA or picrotoxin binding sites $\mathrm{s}^{8,15,23,25,32}$. Benzodiazepine receptor ligands which were convulsant or proconvulsant, such as the $\beta$-carbolines, $\beta$ $\mathrm{CCM}, \beta-\mathrm{CCE}$ and DMCM, and the pyrazoloquinoline, CGS 8216, reduced GABAergic inhibition through an allosteric interaction with the $\mathrm{GABA}_{\mathrm{A}}$ receptor $2,5,8,11,26,34$. Previously, $\alpha$-keto- $\delta$-guanidinovaleric acid was shown to inhibit GABA and Gly responses, probably by blocking their chloride channels ${ }^{7}$.

In an attempt to determine the mechanisms through which arginine, homoarginine and arginic acid might contribute to development of seizures in hyperargininemia, we evaluated the effects of these guanidino compounds on responses evoked by iontophoretically applied GABA and Gly recorded from spinal cord neurons in cell culture.

\section{METHODS}

\section{Primary dissociated cell culture}

Spinal cord neuron cultures were prepared from dissected spinal cords and attached dorsal root ganglia from 12-14-day-old fetal mice as described previously ${ }^{29}$. The tissue was minced and then mechanically dissociated by trituration in $\mathrm{Ca}^{2+}$ - and $\mathrm{Mg}^{2+}$-free balanced salt solution to a suspension of single cells and small clumps. The dissociated cells were suspended in culture medium (90\% Eagle's minimal essential medium supplemented with $5.5 \mathrm{~g} / 1$ of glucose and $1.5 \mathrm{~g} / 1$ of $\mathrm{NaHCO}_{3}, 5 \%$ heat-inactivated horse serum and 5\% Nu-Serum II (Collaborative Research Inc.) (325 mOsmol) and then plated on sterile collagencoated $35 \mathrm{~mm}$ dishes. The cultures were maintained in an incubator with an atmosphere of $93 \%$ room air and $7 \% \mathrm{CO}_{2}$ at $35^{\circ} \mathrm{C}$. The bicarbonate/ $\mathrm{CO}_{2}$ buffer maintained $\mathrm{pH}$ at 7.4. 5-Fluoro-

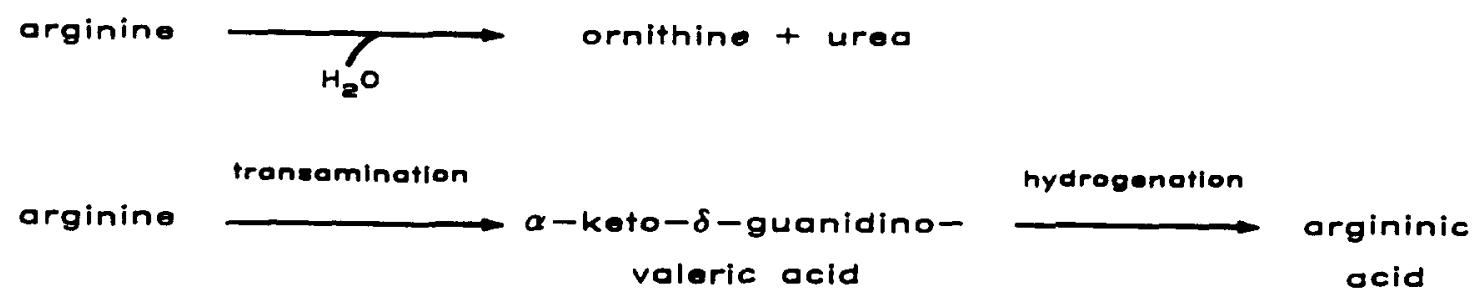

Fig. 1. Arginase deficiency results in the activation of secondary catabolic pathways. 
2 -deoxyuridine was added to the cultures on days 6-8 to suppress the growth of rapidly dividing nonneuronal cells. Medium was changed twice weekly. Cultures werc maintained for 4-9 weeks before electrophysiological experiments.

\section{Experimental procedures}

Solutions. All recordings were made in a Dulbecco's phosphate-buffered saline (DPBS) after removal of growth medium. The DPBS, with elevated magnesium ion concentration in order to suppress spontaneous activity, contained (in $\mathrm{mM}$ ): $\mathrm{NaCl}, 137 ; \mathrm{Na}_{2} \mathrm{HPO}_{4}, 8.06 ; \mathrm{KCl}, 2.68 ; \mathrm{KH}_{2} \mathrm{PO}_{4}$, $1.47 ; \mathrm{CaCl}_{2}, 1 ; \mathrm{MgCl}_{2}, 10$; glucose, $5.6(\mathrm{pH} 7.3-$ 7.4). Heavy paraffin oil was applied to the surface of the bathing solution to retard evaporation. Solutions of drugs were prepared on the day of the experiment in the following manner: arginine hydrochloride, homoarginine hydrochloride, $a$-keto$\delta$-guanidinovaleric acid and argininic acid were dissolved in DPBS to form $10 \mathrm{mM}$ solutions. Aliquots were removed and diluted in bathing medium to obtain the applied solutions. For the study of the influence of the guanidino compounds on GABA responses, arginine, homoarginine, $\alpha$ keto- $\delta$-guanidinovaleric acid and argininic acid were all applied at 1 and $10 \mathrm{mM}$. In addition, $\alpha$ keto- $\delta$-guanidinovaleric acid and argininic acid were applied at $100 \mu \mathrm{M}$. The effects of the guanidino compounds on Gly responses were evaluated at a concentration of $10 \mathrm{mM}$. CGS 9896 , a pyrazoloquinoline previously shown to be a pure benzodiazepine receptor antagonist ${ }^{5}$, was dissolved in dimethylsulfoxide to obtain a $10 \mathrm{mM}$ stock solution. Aliquots were removed and diluted in bathing medium to obtain the applied concentration containing less than $0.1 \%$ of dimethylsulfoxide.

Experimental apparatus. For experiments, the culture dish containing the bathing solution was placed on a stage with temperature regulated at $34-35^{\circ} \mathrm{C}$. The stage was mounted on a Leitz inverted microscope fitted with phase-contrast optics to facilitate micropipette placement (using Leitz micromanipulators) and to penetrate cells under direct visual control.

Electrophysiological recordings. Intracellular recordings were made from the somata of spinal cord neurons ( $>20 \mu \mathrm{m}$ ) using glass micropipettes
(20-25 M $\Omega$ ) filled with $3 \mathrm{M} \mathrm{KCl}$. Use of an active bridge circuit (Dagan 8100 or W-P Instruments M707) allowed simultaneous recording of membrane potential and injection of current (for steady-state polarization or periodic stimulation) using a single micropipette. The preamplifier output was led to a 6-channel polygraph (Gould $2600 \mathrm{~S}$ ) for continuous recording.

$G A B A$ and $G l y$ responses. $\mathrm{GABA}(0.5 \mathrm{M}, \mathrm{pH}$ 3.4) and Gly (0.5 M, pH 3.0) were applied iontophoretically using $500 \mathrm{~ms}$ duration rectangular current pulses at $5 \mathrm{~s}$ intervals. Iontophoretic pipettes were positioned to within $2 \mu \mathrm{m}$ of neuronal somata. The use of $3 \mathrm{M} \mathrm{KCl}$-filled micropipettes shifted the chloride equilibrium potential from about $-65 \mathrm{mV}$ to about $-20 \mathrm{mV}$. Under these conditions, an increase of chloride conductance resulted in an outward chloride current, giving depolarizing GABA and Gly responses ${ }^{23}$. Responses of about $10-15 \mathrm{mV}$ in amplitude were evoked following membrane hyperpolarization $(-70$ to $-90 \mathrm{mV}$ ) to avoid saturation at or near the chloride equilibrium potential. Effects on GABA and Gly responses were accepted only if the responses returned to control amplitude within 5 min of removal of the drug-containing micropipette.

Drug application. The tested guanidino compounds were applied by local superfusion. A blunt-tipped $(5-10 \mu \mathrm{m})$ pipette filled with the test solution was positioned $15-30 \mu \mathrm{m}$ from the suma of the cell under study. The open end of the local superfusion pipette was connected to a pressure regulator, set between 0.4 and 0.8 pounds per square inch (psi), by tight-fitting polyethylene tubing. Pressure pulse duration, regulated by a voltage-activated 3 -way valve, was $10 \mathrm{~s}$. Under these conditions, local superfusion produced no artifacts, and application of control solution (DPBS alone) was free of significant effects. When studying the effect of co-application of the guanidino compounds and the benzodiazepine receptor antagonist CGS 9896, the drugs were applied through one local superfusion pipette to avoid flow artifacts. As a control, DPBS alone applied by diffusion was without effect in this paradigm. The local superfusion pipettes and recording micropipettes were held by Leitz micromanipulators. To decrease leakage of drugs into bathing medium, 
the tips of the local superfusion pipettes were kept in the oil phase between drug application trials. They were lowered into the aqueous phase only when drug application was desired.

Drugs. GABA, Gly and the guanidino compounds arginine, homoarginine and argininic acid were purchased from Sigma Chemical Company (St. Louis, MO, U.S.A.) $\alpha$-keto- $\delta$-guanidinovaleric acid was synthesized enzymatically ${ }^{7}$. Structural formulas of the studied guanidino compounds are shown in Fig. 2. CGS 9896 (2-(4-chlorophenyl)-2,5-dihydropyrazolo-(4,3-C) quinoline-3 (3-H)-one) was obtained from Ciba-Geigy Corp. (Summit, NJ, U.S.A.).

Algebraic and statistical methods. At all applied concentrations, mean values and standard deviations were calculated for the obtained amplitudes of the GABA and Gly responses. The responses obtained during local superfusion of the tested drugs were expressed as percentage of the control responses. The statistical significance of differences between GABA and Gly responses with and without drug application was calculated using the 2-tailed Student's $t$-test; $P<0.05$ was considered statistically significant.

\section{RESULTS}

Direct effects of arginine, homoarginine, $\alpha-k e t o-\delta$ guanidinovaleric acid, argininic acid and CGS 9896 on $G A B A$ responses

Application of arginine and homoarginine at 1

ARGININE

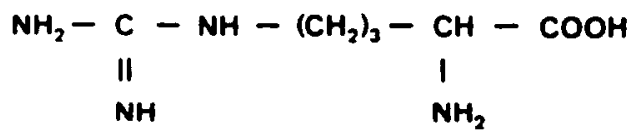

$\alpha$-Koto- $\delta$-GUANIDINOVALERIC ACID

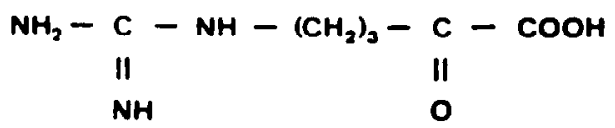

TABLE I

Effects of arginine (Arg), homoarginine (HArg), a-keto- $\delta$ guanidinovaleric acid $(\alpha-k-\delta-G V A)$ and argininic acid (ArgA) on mouse spinal cord neurons

\begin{tabular}{lrll}
\hline & & $\begin{array}{l}\text { Number } \\
\text { of cells } \\
\text { studied }\end{array}$ & $\begin{array}{l}\text { GABA responses } \\
\text { \% of control } \\
\text { (mean } \pm S . D .)\end{array}$ \\
\hline Arg & $1 \mathrm{mM}$ & 5 & $101 \pm 3.54$ \\
& $10 \mathrm{mM}$ & 5 & $49.3 \pm 7.02^{* *}$ \\
HArg & $1 \mathrm{mM}$ & 7 & $98.0 \pm 1.88^{*}$ \\
& $10 \mathrm{mM}$ & 6 & $38.7 \pm 12.9^{* *}$ \\
$\alpha-\mathrm{k}-\delta$-GVA & $100 \mu \mathrm{M}$ & 6 & $96.4 \pm 2.94^{* *}$ \\
& $1 \mathrm{mM}$ & 6 & $51.0 \pm 7.62^{* *}$ \\
& $10 \mathrm{mM}$ & 6 & $13.6 \pm 8.24^{* *}$ \\
ArgA & $100 \mu \mathrm{M}$ & 6 & $95.8 \pm 2.30^{* *}$ \\
& $1 \mathrm{mM}$ & 5 & $45.0 \pm 5.03^{* *}$ \\
& $10 \mathrm{mM}$ & 5 & $0.00 \pm 0.00^{* *}$ \\
\hline
\end{tabular}

${ }^{*} P<0.05 ;{ }^{* *} P<0.01$ compared to controls

and $10 \mathrm{mM}$ and $\alpha$-keto- $\delta$-guanidinovaleric acid and argininic acid at $100 \mu \mathrm{M}, 1 \mathrm{mM}$ and $10 \mathrm{mM}$ did not alter resting membrane potential or conductance. Application of recording solution $(n=16)$ did not significantly alter GABA responses $(0.1 \pm$ $1.7 \%)$. Application of CGS $98961 \mu \mathrm{M}(\mathrm{n}=11)$ was free of significant effects on GABA responses $(0.23 \pm 4.36 \%$ increase $)$. Arginine, homoarginine, $\alpha$-keto- $\delta$-guanidinovaleric acid and argininic acid rapidly and reversibly reduced GABA-responses in a concentration-dependent manner

HOMOARGININE<smiles>N=C(N)NCCC(N)C(=O)O</smiles>

ARGININIC ACIO

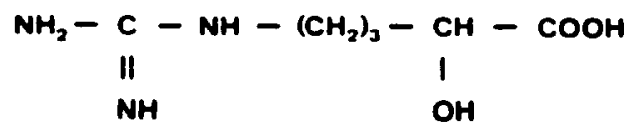

Fig. 2. Structural formulas of arginine, homoarginine, $\alpha$-keto- $\delta$-guanidinovaleric acid and argininic acid. 
PRE

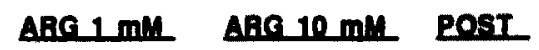

A.<smiles>CC=CC(C)CCCC</smiles><smiles>C=CCCCCCC</smiles>

B.

EAE HARG $1 \mathrm{~mL}$ HABO $10 \mathrm{~mL}$ BOSI

PAE<smiles>CC=CC</smiles>

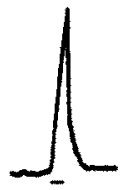

EOST
C.<smiles>CCCCCCCCCCCCC</smiles>

PBE

D.<smiles>CC1CCCCC1C</smiles><smiles>CCCCC</smiles>
$10 \mathrm{~mm}$
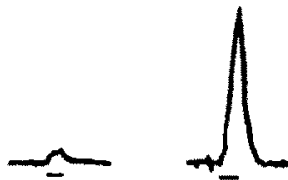

POST

Fig. 3. Reversible, concentration-dependent effects of arginine (ARG) (A), homoargininc (HARG) (B), $\alpha$-keto- $\delta$-guanidinovaleric acid $(\alpha-k-\delta$-GVA) (C) and argininic acid (ARGA) (D) on GABA responses. PRE shows stable GABA responses before drug application. The 2 middle responses show the effect of the superfused drug. GABA responses returned to control values (POST) within 2 min following removal of the guanidino compound-containing micropipette. Iontophoretic application of GABA is indicated with a dash.

(Fig. 3 and Table I). While arginine was devoid of any significant effect on GABA responses at 1 $\mathrm{mM}$, it significantly decreased $\mathrm{GABA}$ responses to $49.3 \pm 7.02 \%$ of control values at $10 \mathrm{mM}$. Homoarginine, $\alpha$-keto- $\delta$-guanidinovaleric acid and argininic acid, at all applied concentrations, significantly reduced GABA responses. Argininic acid completely inhibited GABA responses at 10 $\mathrm{mM}$. Argininic acid was the most potent drug in inhibiting GABA responses, followed, in decreasing
TABLE II

Effects of Arg, HArg, $\alpha-k-\delta-G V A$ and ArgA on Gly responses on mouse neurons in cell culture

\begin{tabular}{llll}
\hline & & $\begin{array}{l}\text { Number } \\
\text { of cells } \\
\text { studied }\end{array}$ & $\begin{array}{l}\text { Gly responses } \\
\% \text { of control } \\
\text { (mean } \pm S . D .)\end{array}$ \\
\hline Arg & $10 \mathrm{mM}$ & 7 & $45.2 \pm 7.12^{* *}$ \\
HArg & $10 \mathrm{mM}$ & 4 & $21.1 \pm 13.4^{* *}$ \\
a-k-a-GVA & $10 \mathrm{mM}$ & 8 & $27.2 \pm 32.5^{* *}$ \\
ArgA & $10 \mathrm{mM}$ & 6 & $7.52 \pm 15.0^{* *}$ \\
\hline
\end{tabular}

**P $P<0.01$ compared to controls.

potency, by $\alpha$-keto- $\delta$-guanidinovaleric acid, homoarginine and arginine.

Direct effects of arginine, homoarginine, $\alpha-k e t o-\delta$ guanidinovaleric acid and argininic acid on Gly responses

Arginine $(10 \mathrm{mM})$ and argininic acid $(10 \mathrm{mM})$ rapidly and reversibly decreased Gly responses (Fig. 4 and Table II). The guanidino compounds

\section{TABLE III}

CGS 9896, a benzodiazepine receptor antagonist, did not influence the effects of Arg, HArg, $\alpha-k-\delta-G V A$ and ArgA on GABA responses on mouse spinal cord neurons

\begin{tabular}{|c|c|c|}
\hline & $\begin{array}{l}\text { Number of } \\
\text { cells } \\
\text { studied }\end{array}$ & $\begin{array}{l}\text { GABA responses } \\
\% \text { of control } \\
\text { (mean } \pm S . D .)\end{array}$ \\
\hline CGS $98961 \mu \mathrm{M}$ & 11 & $100 \pm 4.36$ \\
\hline $\operatorname{Arg} 10 \mathrm{mM}$ & 3 & $45.5 \pm 10.9$ \\
\hline \multicolumn{3}{|l|}{$\operatorname{Arg} 10 \mathrm{mM}$} \\
\hline$+\mathrm{CGS} 98961 \mu \mathrm{M}$ & 3 & $48.0 \pm 10.6$ \\
\hline HArg $10 \mathrm{mM}$ & 3 & $34.4 \pm 10.9$ \\
\hline \multicolumn{3}{|l|}{ HArg $10 \mathrm{mM}$} \\
\hline+ CGS $98961 \mu \mathrm{M}$ & 3 & $39.0 \pm 9.50$ \\
\hline$\alpha-k-\delta-G V A 10 \mathrm{mM}$ & 3 & $18.5 \pm 11.6$ \\
\hline \multicolumn{3}{|l|}{$a-\mathrm{k}-\delta$-GVA $10 \mathrm{mM}$} \\
\hline+ CGS $98961 \mu \mathrm{M}$ & 3 & $18.5 \pm 10.0$ \\
\hline $\operatorname{ArgA} 10 \mathrm{mM}$ & 3 & $0.00 \pm 0.00$ \\
\hline \multicolumn{3}{|l|}{$\operatorname{ArgA} 10 \mathrm{mM}$} \\
\hline+ CGS $98961 \mu \mathrm{M}$ & 3 & $0.00 \pm 0.00$ \\
\hline
\end{tabular}

No statistical differences were found for the paired samples (indicated by a vertical line). 


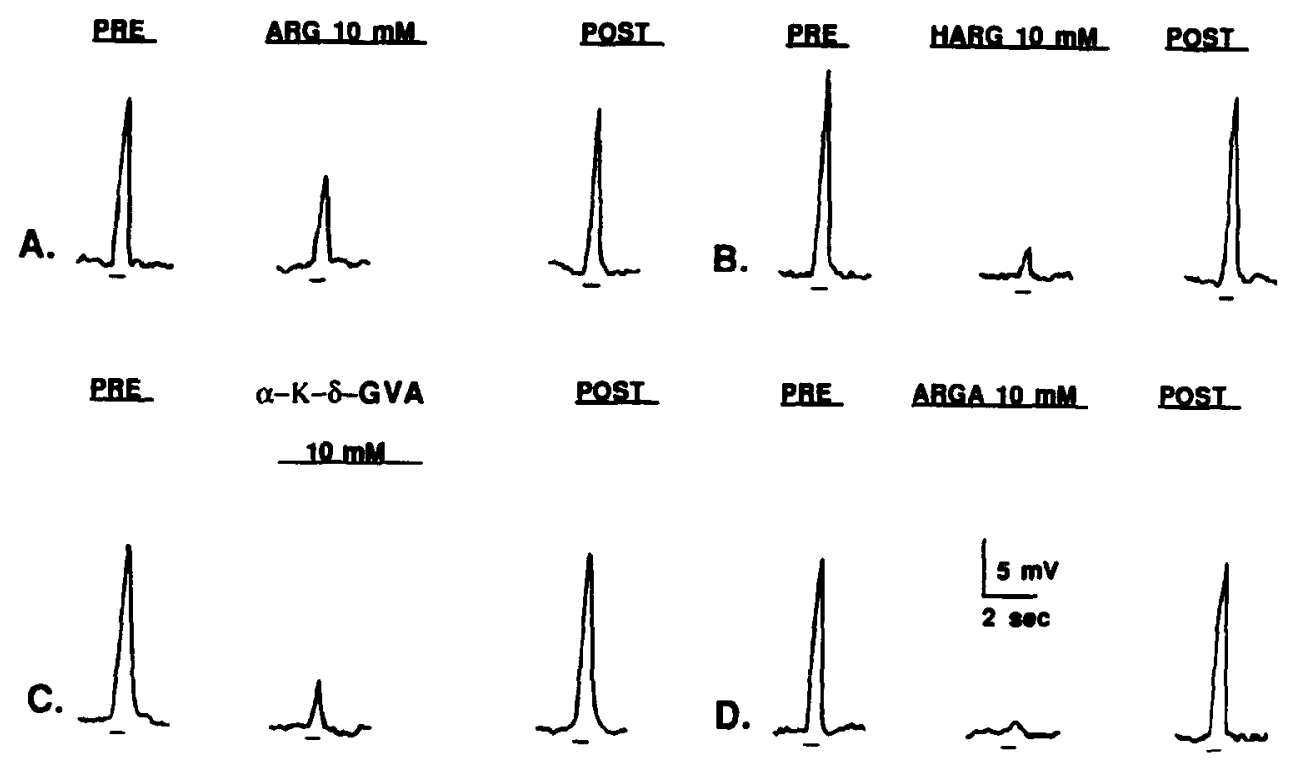

Fig. 4. Reversible effects of arginine (10 mM) (A), homoarginine (10 mM) (B), $\alpha$-keto- $\delta$-guanidinovaleric acid (10 mM) (C) and argininic acid (10 mM) (D) on Gly responses on spinal cord neurons. PRE shows stable Gly responses before drug application. The middle responses shows the effect of the superfused drug. Gly responses returned to control values (POST) within 2 min following removal of the guanidino compound-containing micropipette. Iontophoretic application of Gly is indicated with a dash.

were equally effective in decreasing Gly and GABA responses.

Effects of co-application of arginine, homoarginine, $\alpha$-keto- $\delta$-guanidinovaleric acid and argininic acid with CGS 9896 on $G A B A$ responses

The effects of arginine $(10 \mathrm{mM})$, homoarginine $(10 \mathrm{mM}), \alpha$-keto- $\delta$-guanidinovaleric acid $(10 \mathrm{mM})$ and argininic acid $(10 \mathrm{mM})$ alone or in combination with CGS $9896(1 \mu \mathrm{M})$, a benzodiazepine receptor antagonist, were not significantly different (Table III).

\section{DISCUSSION}

We have studied the effects of 4 guanidino compounds that were found to be increased in cerebrospinal fluid of hyperargininemia patients on responses to the iontophoretically applied inhibitory neurotransmitters GABA and Gly on mouse neurons in primary dissociated cell culture. The guanidino compounds were arginine, homoarginine, $\alpha$ keto- $\delta$-guanidinovaleric acid and argininic acid.

Arginine, homoarginine, $\alpha$-keto- $\delta$-guanidinovaleric acid and argininic acid inhibited GABA responses on mouse spinal cord neurons in cell cul- ture in a concentration-dependent manner and inhibited Gly responses at a concentration of 10 $\mathrm{mM}$. Argininic acid was the most potent in inhibiting responses to inhibitory amino acids, followed in decreasing potency by $\alpha$-keto- $\delta$-guanidinovaleric acid, homoarginine and arginine. The observed inhibition of GABA responses was not mediated through the benzodiazepine receptor: CGS 9896, a pyrazoloquinoline and benzodiazepine receptor antagonist ${ }^{5}$, did not antagonize the guanidino compound-induced inhibition of GABA responses. Earlier studies on neurons in culture demonstrated that the inhibitory neurotransmitters GABA and Gly act through different receptors on the membrane surface ${ }^{22,29}$. Moreover, activation of chloride conductance has been demonstrated to underlie the GABA and Gly receptor-coupled events. Since GABA and Gly exert their inhibitory effects by activation of chloride conductance through interaction with different receptors, our observations suggest that arginine, homoarginine, $\alpha$-keto- $\delta$-guanidinovaleric acid and argininic acid, shown here not to be benzodiazepine receptor ligands, inhibit inhibitory amino acid-responses by blocking chloride channels.

Although only observed at concentrations 
higher than those hitherto found in cerebrospinal fluid, the inhibitory effects of arginine, homoarginine, $\alpha$-keto- $\delta$-guanidinovaleric acid and argininic acid on inhibitory neurotransmitter responses might have pathophysiological importance. Indeed, when evaluating the possible neurotoxicity of a given compound, one should take into account the possibility of an increased susceptibility of the diseased subject as well as the possible accumulation of the substance in brain tissue. Moreover, the studied guanidino compounds might have, perhaps in combination with still other toxins, additive effects. Two guanidino compounds found to accumulate in CSF of uremic patients ${ }^{6}$, guanidine and methylguanidine, had an additive inhibitory effect on responses to the inhibitory neurotransmitters GABA and Gly (DeDeyn and Macdonald, unpublished observations). An additive effect has also been shown for creatinine, creatine, guanidinoacetic acid and guanidine in an experimental paradigm testing in vitro autohemolysis ${ }^{10}$. Earlier reports demonstrated $\alpha$-keto- $\delta$-guanidinovaleric acid $^{16}$ to be more potent than homoarginine ${ }^{41}$ in inducing seizures in rabbit and rat, respectively.

\section{REFERENCES}

1 Bernar, J., Hanson, R.A., Kern, R., Phoenix, B., Shaw, K.N.F. and Cederbaum, S.D., Arginase deficiency in a 12year-old boy with mild impairment of intellectual function, J. Pediatr, 108 (1986) 432-435.

2 Braestrup, C., Nielsen, M., Honore, T., Jensen, L.H. and Petersen, E.N., Benzodiazepine receptor ligands with positive and negative efficacy, Neuropharmacology, 22 (1983) 1451-1457.

3 Cederbaum, S.D., Shaw, K.N.F. and Valente, M., Hyperargininemia, J. Pediatr., 90 (1977) 569-573.

4 Cederbaum, S.D., Shaw, K.N.V., Spector, E.B., Verity, M.A., Snodgrass, P.J. and Sugarman, G.I., Hyperargininemia with arginase deficiency, Pediatr. Res., 13 (1979) 827.

5 DeDeyn, P.P. and Macdonald, R.L., CGS 9896 and ZK 91296, but not CSG 8216 and Ro 16-1788, are pure benzodiazepine receptor antagonists on mouse neurons in cell culture, J. Pharmacol. Exp. Ther, 242 (1987) 48-55.

6 DeDeyn, P.P., Marescau, B., Cuykens, J.J., Van Gorp, L. and Lowenthal, A., Guanidino compounds in serum and cerebrospinal fluid of nondialyzed patients with renal insufficiency, Clin. Chim. Acta, 167 (1987) 81-88.

7 DeDeyn, P.P., Marescau, B. and Macdonald, R.L., Effects of $\alpha$-keto- $\delta$-guanidinovaleric acid on inhibitory amino
This is in agreement with the higher potency of $\alpha$ keto- $\delta$-guanidinovaleric acid in decreasing responses to the inhibitory neurotransmitters GABA and Gly as illustrated in this report. The least potent guanidino compound in decreasing GABA responses, applied at a single concentration of $0.1 \mathrm{M}$ in rabbit, was devoid of any effects on the electroencephalogram ${ }^{16}$. The in vivo epileptogenicity of argininic acid has not been reported. If reduction of postsynaptic responses to inhibitory neurotransmitters underlies the epileptogenicity of these guanidino compounds, our results would suggest that argininic acid might be a more potent convulsant than $\alpha$-keto- $\delta$-guanidinovaleric acid.

\section{ACKNOWLEDGEMENTS}

The authors wish to thank Ms Nancy Ciliax for technical assistance and Ms Tina Van Craenenbroeck and Ms Mikki Thompson for secretarial work. Financial support was provided by the US Public Health Service (Grant NS 19613), the NATO and the Born-Bunge Foundation. acid responses on mouse neurons in cell culture, Brain Res., 449 (1988) 54-60.

8 DeDeyn, P.P. and Macdonald, R.L., Effects of antiepileptic drugs on GABA responses and on reduction of GABA responses by $\mathrm{PTZ}$ and DMCM on mouse neurons in cell culture, Epilepsia, 30 (1989) 17-25.

9 Endres, W., Schaller, R. and Shin, Y.S., Diagnosis and treatment of argininaemia. Characteristics of arginase in human erythrocytes and tissues, J. Inher. Metabol. Dis, 7 (1984) 8

10 Giovannetti, S., Cioni, L., Balestri, P.L. and Biagini, M., Evidence that guanidino compounds and some related compounds cause hemolysis in chronic uremia, Clin. Sci., 34 (1968) 141-148.

11 Jensen, M.S. and Lambert, J.D.C., The interaction of the $\beta$-carboline derivative DMCM with inhibitory amino acid responses on cultured mouse neurons, Neurosci. Lett., 40 (1983) 175-179.

12 Jorda, A., Rubio, V., Portoles, M., Vilas, J. and GarciaPino, J., A new case of arginase deficiency in a Spanish male, J. Inher. Metabol. Dis., 9 (1986) 393-397.

13 Kang, S.S., Wong, P.W.K. and Milyn, M.A., Hyperaginincmia: effect of ornithine and lysine supplementation, $J$. Pediatr., 103 (1983) 763-765. 
14 Loyd, K.G., Munari, C., Bossi, L., Stoeffels, C., Talairach, J. and Morselli, P., Biochemical evidence for the alterations of GABA-mediated synaptic transmission in pathological brain tissue (stereo EEG or morphological definition) from epileptic patients. In: P.L. Morselli, K.G. Lloyd and W. Löscher (Eds.), Neuro-transmitters, Seizures and Epilepsy, Raven Press, New York, 1981, pp. 325-338.

15 Macdonald, R.L. and Barker, J.L., Specific antagonism of GABA-mediated postsynaptic inhibition in cultured mammalian spinal cord neurons: a common mode of convulsant action, Neurology, 28 (1978) 325-330.

16 Marescau, B., Hiramatsu, M. and Mori, A., $\alpha$-keto- $\delta$ guanidinovaleric acid-induced electroencephalographic epileptiform discharges in rabbits, Neurochem. Pathol., 1 (1983) 203-209.

17 Marescau, B., Qureshi, I.A., DeDeyn, P., Letarte, J., Ryba, R. and Lowenthal, A., Guanidino compounds in plasma, urine and cerebrospinal fluid of hyperargininemic patients during therapy, Clin. Chim. Acta, 146 (1985) 21-27.

18 Marescau, B., DeDeyn, P.P., Lowenthal, A. et al. Guanidino compound analysis as a complementary diagnostic parameter for hyperagininemia: follow-up of guanidino compound levels during therapy, Pediatr. Res., in press.

19 Meldrum, B., Convulsant drugs, anticonvulsants and GABA-mediated neuronal inhibition, In: P KrogsgaardLarsen, J. Scheel-Kruger and H. Kofod (Eds.), Neurotransmitters, Munksgaard, Copenhagen, 1979, pp. 390-405.

20 Michels, V.V. and Beaudet, A.L., Arginase deficiency in multiple tissues in argininemia, Clin. Genet., 13 (1978) 61-67.

21 Mizutani, N., Machaca, M., Hayokawa, C., Kato, T., Watanabe, K. and Suzuki, S., Hyperagininemia: clinical course and treatment with sodium benzoate and phenylacetic acid, Brain Dev., 5 (1983) 555-563.

22 Nelson, P.G., Ransom, B.R., Henkart, M. and Bullock, P.N., Mouse spinal cord in cell culture, IV. Modulation of inhibitory synaptic function, $J$. Neurophysiol., 40 (1977) 1178-1187.

23 Nowak, L.M., Young, A.B. and Macdonald, R.L., GABA and bicuculline action on mouse spinal cord and cortical neurons in cell culture, Brain Res., 244 (1982) 155-164.

24 Olsen, R.W., The GABA-postsynaptic membrane receptor-ionophore complex: site of action of convulsant and anticonvulsant drugs, Mol. Cell. Biochem., 39 (1981) 261-279.

25 Olsen, R.W. and Leeb-Lundberg, F, Convulsant and anticonvulsant drug binding sites related to GABA-regulated chloride ion channels. In: E. Costa, G. Di Chiara and G.L. Gessa (Eds.), GABA and Benzodiazepine Receptors, Raven Press, New York, 1981, pp. 93-102.

26 Petersen, E.N., DMCM: potent convulsive benzodiazepine receptor ligand, Eur. J. Pharmacol., 94 (1983) 117-124.

27 Qureshi, I.A., Letarte, J., Ouellet, R., Lelievre, M. and Laberge, C., Ammonia metabolism in a family affected by hyperargininemia, Diab. Metabol., 7 (1981) 5-11.
28 Qureshi, I.A., Letarte, J., Ouellet, R. and Larochelle, J., A new French-Canadian family affected by Hyperargininemia, J. Inher. Metabol. Dis., 6(1983) 173-182.

29 Ransom, B.R., Bullock, P.N. and Nelson, P.G., Mouse spinal cord in cell culture, III. Neuronal chemosensitivity and its relationship to synaptic activity, $J$. Neurophysiol., 40 (1977) 1163-1177.

30 Roberts, E., Epilepsy and antiepileptic drugs: A speculative synthesis. In: G.H. Glaser, J.K. Penry and H.D. Woodbury (Eds.), Antiepileptic Drugs: Mechanisms of Action, Raven Press, New York, 1980, pp. 667-713.

31 Sakiyama, T., Nakobayashi, H., Kondo, Y., Shimizu, H., Kodama, S. and Kitagawa, T., Argininemia: clinical course and trial of enzyme replacement therapy, Biomed. Therapeut., (Tokyo), 8 (1982) 907-910 (in Japanese).

32 Schofield, C.N., Leptazol antagonizes the postsynaptic actions, of $\gamma$-aminobutyric acid, Br. J. Pharmacol., 63 (1978) 495-502.

33 Schofield, P.R., Darlison, M.G., Fujita, N., Burt, D.R., Stephenson, F.A., Rodriguez, H., Rhec, L.M., Ramachandran, J., Reale, V., Glencorse, T.A., Seeburg, P.H, and Barnard, E.A., Sequential and functional expression of the $\mathrm{GABA}_{\mathrm{A}}$ receptor shows a ligand gated receptor superfamily, Nature, 328 (1987) 221-227.

34 Skerritt, J.H. and Macdonald, R.L., Benzodiazepine receptor ligand actions of GABA responses; $\beta$-carbolines, purines, Eur. J. Pharmacol., 101 (1984) 135-141.

35 Snyderman, S.E., Sansaricq, C., Chen, W.J., Norton, P.M. and Phansalkar, S.V., Argininemia, J. Pediatr., 90 (1977) 563-568.

36 Snyderman, S.E., Sansaricq, C., Norton, P.M. and Goldstein, F., Argininemia treated from birth, J. Pediatr., (1979) 61-63.

37 Terheggen, H.G., Schwenk, A., Lowenthal, A., Van Sande, M. and Colombo, J.P., Argininaemia with arginase deficiency, Lancet, ii (1969) 748-749.

38 Terheggen, H.G., Schwenk, A., Lowenthal, A., Van Sande, M. and Colombo, J.P., Hyperargininämie mit Arginasedefekt: eine neue familiare Stoffwechselstörung, I. Klinische Befünde, Z. Kinderheilk., 107 (1970) 298-312.

39 Terheggen, H.G., Schwenk, A., Lowenthal, A., Van Sande, M. and Colombo, J.P., Hyperargininämie mit Arginasedefekt: eine neue familiare Stoffwechselstörung, II. Biochemische Untersuchungen, Z. Kinderheilk., 107 (1970) 313-323.

40 Terheggen, H.G., Lowenthal, A., Lavinha, F. and Colombo, J.P., Familial Hyperargininemia, Arch. Dis. Child., 50 (1975) 57-62.

41 Yokoi, I., Toma, J. and Mori, A., The effect of homoarginine on the EEG of rats, Neurochem. Pathol., 2 (1984) 295-300.

42 Yoshino, M., Kubota, K., Yoshida, I., Murakani, I. and Yamashito, F., Argininemia: report of a new case and mechanisms of ortic aciduria and Hyperargininemia, In: A. Lowenthal, A. Mori, and B. Marescau (Eds.), Urea Cycle Disease. Advances in Experimental Medicine and Biology, Vol. 153, Plenum Press, New York, 1982, pp. 121-125. 